\title{
Cone-Beam Computed Tomography in Periodontal Diagnosis and Treatment Planning
}

\author{
Aparna C. Murali ${ }^{1}$ Rahul Bhandary ${ }^{1}$ \\ ${ }^{1}$ Department of Periodontics, AB Shetty Memorial Institiute of Dental \\ Sciences, Nitte (Deemed to be University), Deralakatte, Mangalore, \\ Karnataka, India \\ J Health Allied Sci ${ }^{\mathrm{NU}}$ 2022;12:343-349.
}

\begin{abstract}
Address for correspondence Aparna C Murali, MDS, Department of Periodontics, AB Shetty Memorial Institiute of Dental Sciences, Nitte (Deemed to be University), Derlakatte, Mangalore, Karnataka, 575018, India (e-mail: aparnacmurali@gmail.com).
\end{abstract}

\begin{abstract}
Diagnosis of periodontal disease depends on conventional clinical parameters. In periodontitis with extensive bone defects, radiographs play a crucial role in arriving at a proper diagnosis. The emergence of cone-beam computed tomography (CBCT) became a boon in oral radiology. Limitations of conventional two-dimensional (2D)

Keywords

- $\mathrm{CBCT}$

- periodontics

- implant planning

- radiography radiographs include inadequate visualization of bone defects, lamina dura, and furcation involvement. CBCT generates 3D images of anatomical structures necessary for the periodontal diagnosis of furcation involvement, intrabony defects, and implant placement. CBCT, thus, imparts various potential applications in the field of periodontics which serves to arrive at better diagnostic conclusions.
\end{abstract}

\section{Introduction}

Periodontal disease is considered being a dreadful microbial disease that affects tooth-supporting structures. ${ }^{1}$ Extensive case recording and radiological evaluation are crucial for successful treatment outcomes in such patients. ${ }^{2}$ The conventional periodontal diagnostic approaches include recording pocket probing depth, bleeding on probing, clinical attachment loss, and intraoral radiography, which plays a vital role in diagnosing the type and amount of alveolar defect. ${ }^{3}$ At present, conventional diagnostic techniques have drawn various limitations that have put clinicians to look at other alternative methods, which would help provide a better diagnosis.

Intraoral radiography is the most familiar diagnostic technique used in periodontics. Its major limitation is its inability to provide a three-dimensional (3D) view of the anatomic structures. Hence, it can affect the interpretation and identification of the defect. The technique also underestimates the amount of bone loss and fails in identifying various anatomical landmarks. ${ }^{4-6}$

published online

January 18, 2022
DOI https://doi.org/ 10.1055/s-0041-1741412. ISSN 2582-4287.
With the introduction of computed tomography (CT) to the medical field, the possibility of visualizing through a 3D image has come true. However, the high cost incurred by the tool and the amount of radiation emitted by it limit the usage of this technology in the dental field.

Cone-beam computed tomography (CBCT) is comparatively a newly emerged diagnostic technology. They have received massive appreciation in dental maxillofacial surgery. ${ }^{7,8}$

The technique offers numerous advantages, such as the low cost incurred by the equipment and lower radiation emission. ${ }^{9}$ The method uses an X-ray source that produces a cone beam of radiation, unlike in CT, where it emits a fan beam-like radiation. ${ }^{10}$

The system consists of a flat panel detector, an image intensifier, and a detector. The source and detector directly connect to a platform to produce sequential planar images as the sensor rotates around the object. The entire scanning completes in a single rotation. Therefore, it can tremendously reduce the radiation exposure to the person. ${ }^{11}$ When we compare the exposure dose of panoramic radiograph with

\footnotetext{
(c) 2022. Nitte (Deemed to be University). All rights reserved. This is an open access article published by Thieme under the terms of the Creative Commons Attribution-NonDerivative-NonCommercial-License, permitting copying and reproduction so long as the original work is given appropriate credit. Contents may not be used for commercial purposes, or adapted, remixed, transformed or built upon. (https://creativecommons.org/ licenses/by-nc-nd/4.0/)

Thieme Medical and Scientific Publishers Pvt. Ltd., A-12, 2nd Floor, Sector 2, Noida-201301 UP, India
} 
that of periapical, it is around 0.0063 and $0.0012 \mathrm{mGy}$, respectively. ${ }^{12}$ Reports also suggest a dose range within 33 to $84 \mathrm{~Sv}$ for performing intraoral estimation. ${ }^{13}$

The application of CBCT widely spreads among fields including dentoalveolar surgeries, implantology, general/ specialized dentistry (orthodontics, periodontics, endodontics, and forensic dentistry). ${ }^{14-17}$

The article here focuses on the different applications of CBCT in the field of periodontics.

\section{Soft Tissue Assessment}

Assessing facial soft tissue thickness plays an integral role in the treatment plan and the degree of success in various periodontal procedures. Even though several methods have emerged to measure soft tissue, the accuracy of these techniques is still under debate.

The literature provides numerous studies supporting the application of CBCT to determine the measurements of hard tissue, while publications are very scarce concerning soft tissue assessment. ${ }^{18}$

In a study conducted by Alessandro et al in 2008, they devised a new technique based on the principle of CBCT, known as soft tissue CBCT (ST CBCT), which helps visualize and estimate the distances respective to hard-soft tissues as well. The technique was simple and non-invasive. Thus, clinicians found it helpful in determining the association between various structures of the periodontium.

Three patients with distinct periodontal biotypes were asked to obtain two separate CBCT scans for the study. The first scan followed the standard methods, while the second used the ST CBCT method. The routine scan could only procure the distance between the cementoenamel junction and the facial bone crest and the width of the alveolar bone. In contrast, the ST CBC scans showed better visualization and accurate measurements of periodontal structures. ${ }^{19}$ Thus, the latter plays a significant role in determining the dimensions of various structures in the periodontium.

However, certain studies have depicted that the technique can't be used as a precise tool for assessing soft tissues.

A study conducted by Gupta et al in 2015 evaluated the thickness of palatal masticatory mucosa through the CBCT scan, along with bone sounding conducted on 20 patients assigned palatal surgery. They found no significant differences among the two groups. However, the results could not be generalized as the sample size was inadequate and not accurately determined (-Table $\mathbf{1}){ }^{20}$

\section{Periodontal Ligament Space}

The status of the lamina dura in a radiograph marks as an early sign for the detection of periodontitis. Periodontal diseases are accompanied in most cases by a discontinuity of the lamina dura.

An imaging technique with a higher sensitivity would be required to detect variations in the periodontal ligament space. As conventional imaging modalities pose several disadvantages such as overlapping, processing errors, or errors in patient positions, clinicians look forward to novel innovations like CBCT to address these issues. ${ }^{21}$
Ozmeric et al compared CBCT and conventional radiographs by creating an artificial periodontal ligament space in a phantom model. The results showed that periapical radiographs were superior to $\mathrm{CBCT}$ in regard to estimating the periodontal ligament space. $^{22}$

A series of in vitro studies were used in an artificial periodontal ligament (PDL) model to compare the images of CBCT and radicular grooves (RGs). The images were presented to 20 people including dentists, dental assistants, and students. Weeks later, the same photos were mixed and given to the same subjects. The results showed a significant difference, where RGs elicited better images compared with CBCT.

However, detailed studies on assessing minor slice/window level techniques for image optimization are required to validate these results further. ${ }^{23}$

\section{Alveolar Bone Defect}

The accurate detection of the alveolar bone defects depends upon the precision of the radiograph taken. Usually, 2D radiographs are insufficient for evaluating bone defects. This is due to various reasons such as obstruction of spongious bone changes in the cortical plate or blurring of anatomic bone structures.

With the addition of a third diagnostic plane, images generated were more precise and accurately determined, especially in a buccolingual direction. ${ }^{24}$

A study conducted by Balasundaram in 2014 showed CBCT scanners as a reliable source for quantitative information on periodontal bone levels. However, accuracy in the anterior jaw was unsatisfactory. ${ }^{25}$

Another study conducted by Vandenberghe et al compared defect measurements in CBCT with intraoral digital radiographs. The results showed intraoral imaging with a better image detail accuracy, while CBCT illustrated a more appropriate morphological assessment of defects. ${ }^{26}$ However, in cross-sectional sections, CBCT measurements were considered to have better accuracy than digital imaging. ${ }^{27}$

Similarly, Misch and colleagues suggested that the CT system exhibited intraoral measurements as equivalent and authentic as clinical calibrations and radiographs. ${ }^{28}$

In a case report by Mohan et al in 2014, a patient reported with a complaint of loose teeth. Clinical and direct digital radiography failed to accurately assess the extent of the periodontal lesion. With the means of CBCT imaging, the detailed morphology of the defects was attained. Post-surgically, the CBCT measurements were also found to be exactly identical to the actual intrasurgical measurements (-Fig. 1). ${ }^{29}$

Mengel et al and Noujeim et al were few among the many remaining authors who have also validated the potentiality of this approach in estimating intrabony defects in their studies. $^{30,31}$

A systematic review done by Haas et al assessed the capability of CBCT in estimating alveolar defects. The results showed a moderate amount of evidence, supporting its role as an appropriate imaging modality, yet also mentioned not to be selected as clinicians first choice for Perio assessment. ${ }^{32}$ 


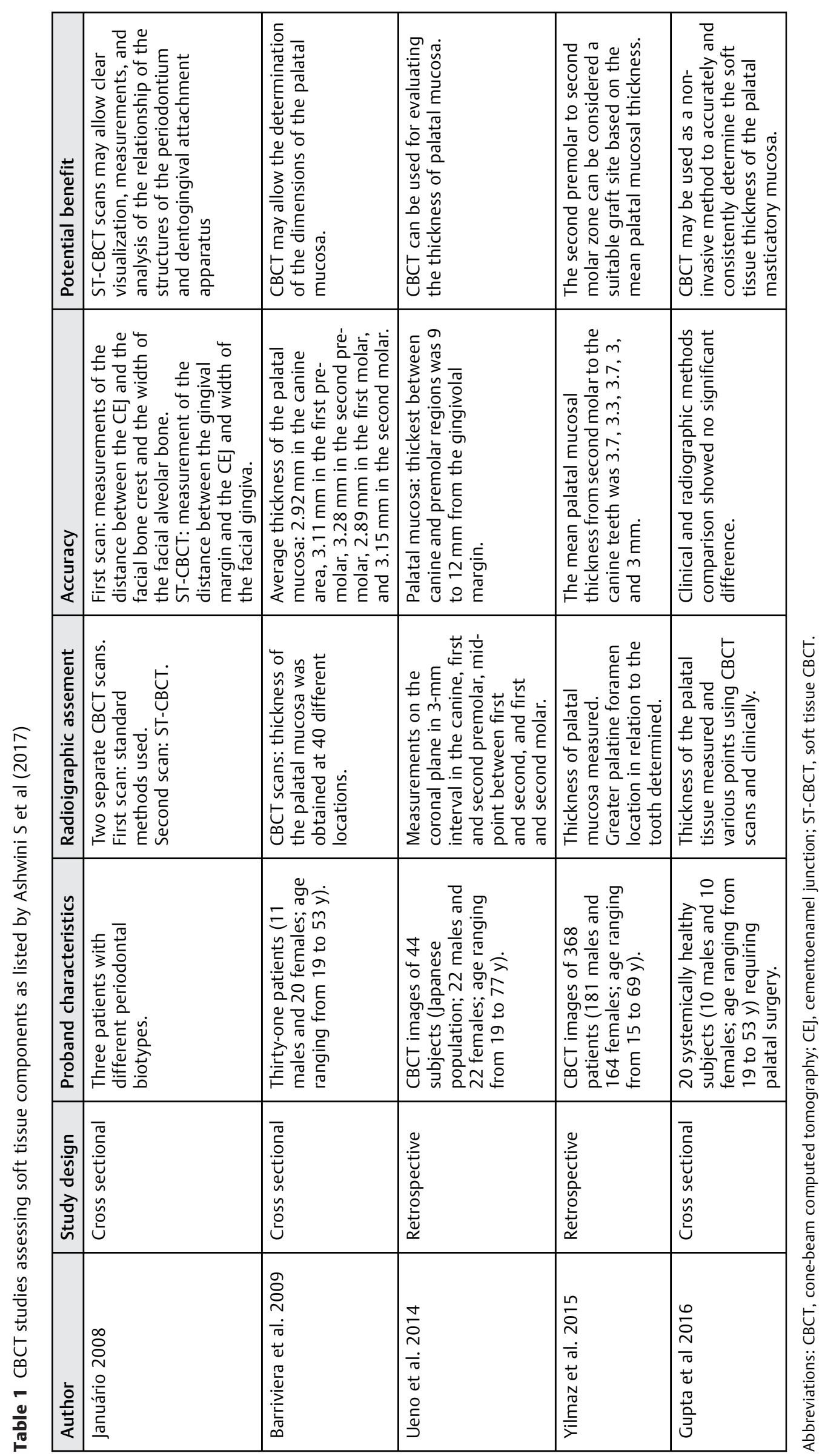




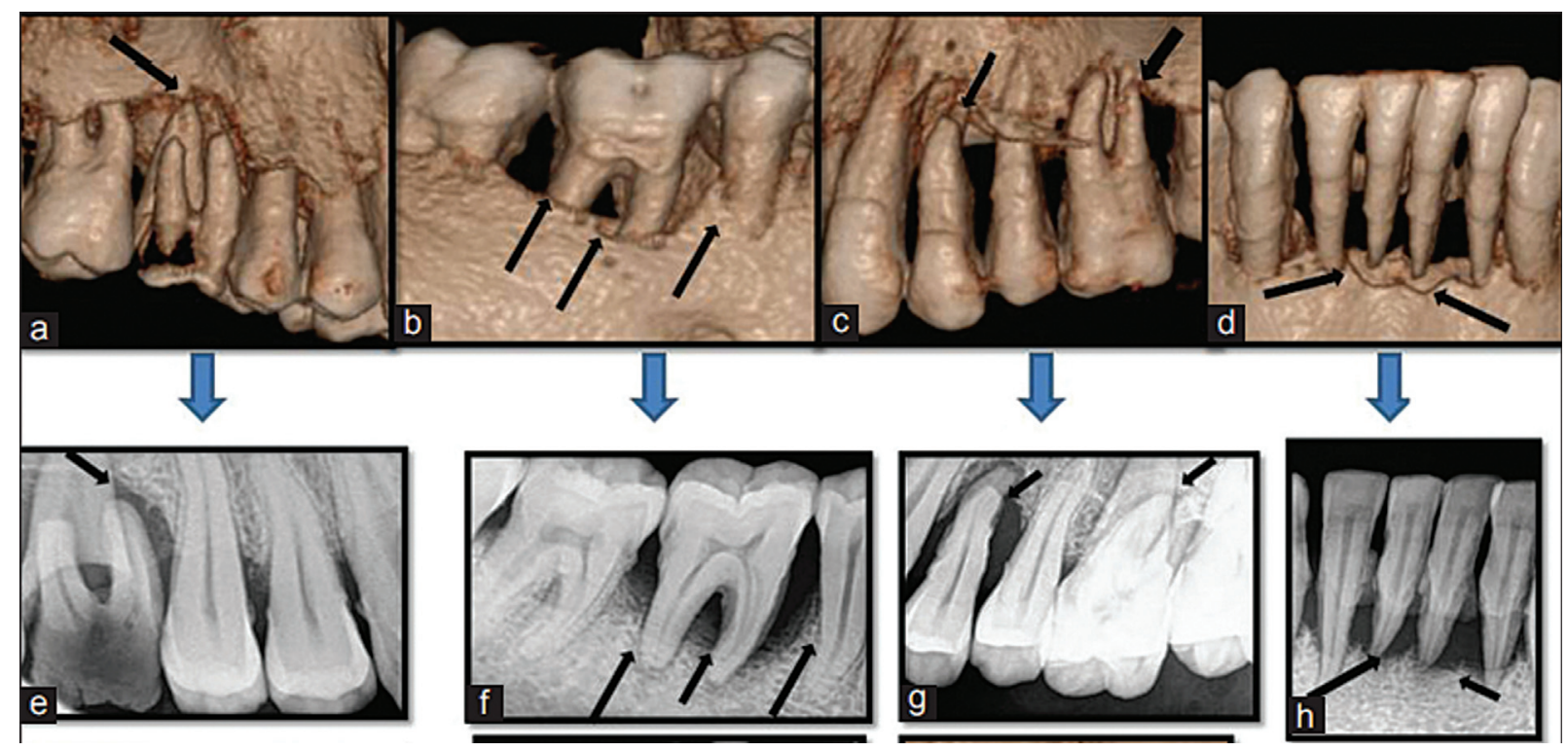

Fig. 1 3D volumetric CBCT images (a, b, c, d), in the areas of maxillary and mandibular arch with 2D digital periapical radiographs (e, f, $\mathbf{g}, \mathbf{h}$ ) from the study by Mohan et al. ${ }^{29}$

Also, available literature was unable to arrive at a consensus regarding the efficacy between $\mathrm{CBCT}$ and in situ measurements. Studies constantly depicted contradictory results.

A possible technical limitation of under- or over-estimation of values was pointed out by numerous clinicians through this scan. A valid justification for this could be the differences in the voxel sizes. ${ }^{33,34}$

The influence of co-variables such as the probing force, probe diameter, and presence of granulation tissue may also suggest the discrepancies between the two routes. ${ }^{27,33}$

Moreover, access and visualization pose a challenge in direct clinical calibration. ${ }^{35}$

\section{Furcation Involvement}

Furcation involvement commences once the attachment loss progresses up to the level of root furcation. Furcation involvement possesses two components: horizontal defect depth and vertical depth. Anatomical variations like cervical enamel pearls, length of root trunk, root anatomy, and root entrance dimensions can influence horizontal and vertical dimensions.

An integral step in assessing furcation involves estimating radicular bone loss. Conventional radiographs, however, might fail in determining the bone support in the intraradicular area, especially in the maxillary molar area.

CBCT images have provided detailed data on the furcation involvement of maxillary molars. ${ }^{36}$ Umetsubo et al in their in vitro study done in pig mandibles reported that CBCT images showed an accuracy within a range of 78 to $88 \%$, suggesting its potentiality in the detection of furcation defects. $^{37}$

In the in vitro assessment conducted by Vandenberghe et al, he compared the results obtained from cone-beam and intraoral radiography. They concluded that the latter failed to accurately detect crater defects and furcation involvement in approximately 29 and $44 \%$ of cases, respectively, while CBCT demonstrated $100 \%$ detectability for both cases. ${ }^{27}$

Similarly, Walter et al reported $84 \%$ data accuracy in surgical assessments taken before and after the furcation surgery in maxillary molars of 14 selected subjects. His reports suggested $\mathrm{CBCT}$ holding more weightage compared with conventional and clinical measurements. ${ }^{36}$

Milena et al from Belgrade University Serbia conducted a clinical examination to compare the diagnostic efficiency in clinical probing and cone-beam radiography for furcation involvement in periodontitis patients. Furcation was assessed at three sites in maxillary molars and two sites in mandibular teeth. The number of diseased sites revealed by СВCT was higher compared with digital probing after the study, hence supporting its adjunctive role in FI assessment. Buccal furcation involvement was denoted positive in CBCT scans but was unable to be detected clinically by probing. ${ }^{38}$

Pajnigara et al conducted a study to assess the dimensions of furcation defects clinically, intrasurgically, and through CBCT. Pre- and post-surgical evaluation and photographs were taken by the clinicians after 6 months. The study group consisted of 40 subjects with grade II furcation defects, treated with demineralized freezed-dried allograft. Statistical significance was noted between pre-surgery clinical and CBCT measurements with post-surgery CBCT and clinical values in vertical and horizontal aspects of the defect. The authors suggested that $\mathrm{CBCT}$ is an advisable diagnostic tool in furcation defects for advanced periodontal disease (- Figs. 2 and $\mathbf{3}$ ). ${ }^{39}$

Furcation-involved teeth usually possess less successful treatment outcomes and a poorer long-term prognosis. Accurate detection in such cases is, therefore, crucial in formulating an appropriate treatment plan. Thus, СВCT enables the clinicians to adequately visualize the furcation defects and compare the data with clinical measurements to manage such clinical cases efficiently. 

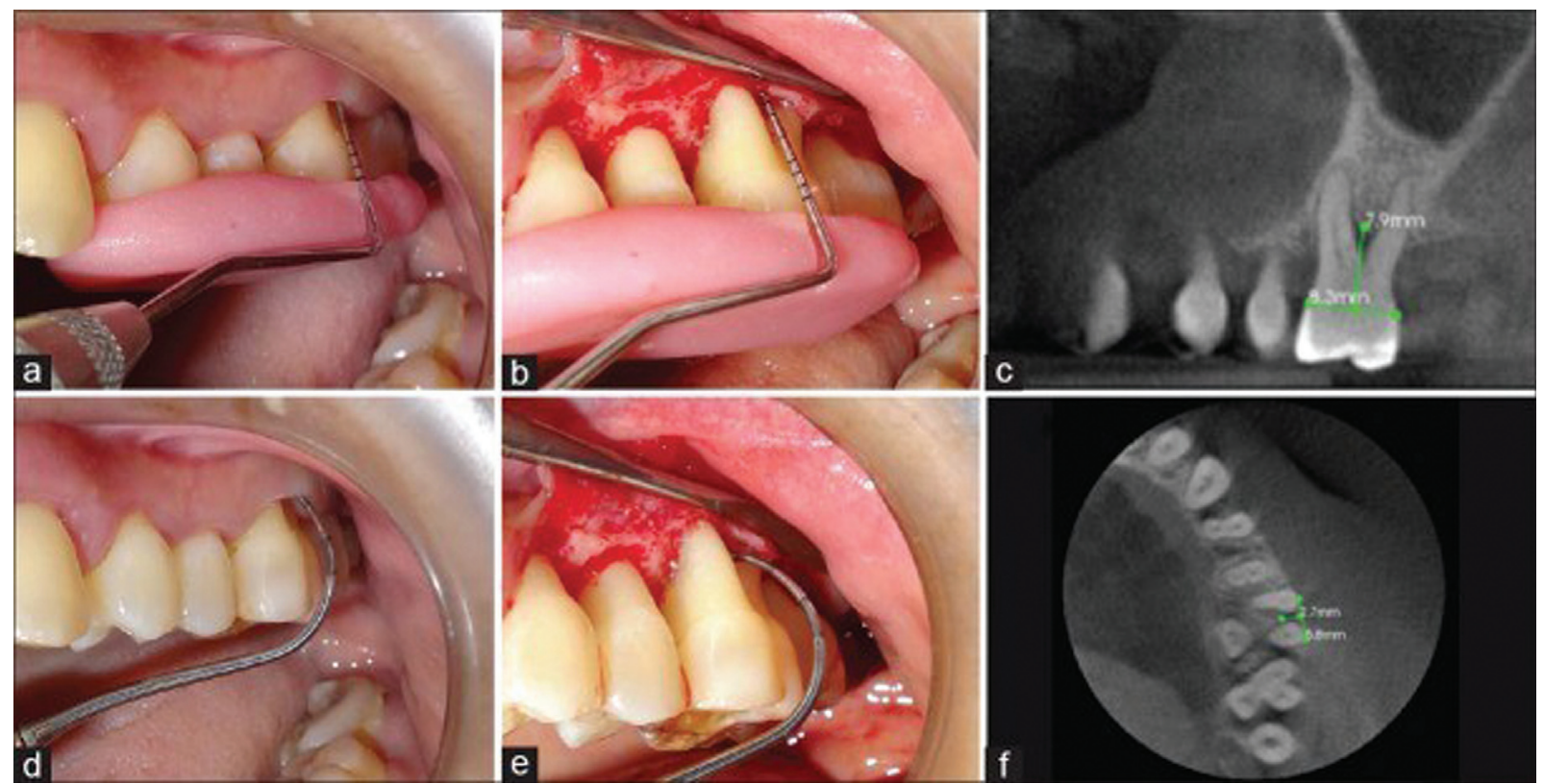

Fig. 2 Pre-operative measurements of furcation defects from Pajnigara et al study. ${ }^{39}$ (a) Clinical measurement of the vertical component. (b) Intrasurgical measurement of the vertical component. (c) CBCT measurement of the vertical component. (d) Clinical measurement of horizontal component. (e) Intrasurgical measurement of horizontal component. (f) CBCT measurement of horizontal component.

\section{Regenerative Periodontal Therapy and Bone Graft}

Cone beam techniques were also investigated for bone level detection following regenerative periodontal procedures.

A similar study was conducted by Grimard et al who compared direct clinical, periapical radiograph, and CBCT measurements for detecting bone-level differences. They evaluated the changes in 35 intrabony defects, which were followed by regenerative periodontal therapy. CT provided more definitive measurements compared with periapical radiographs. Thus, it is inferred as a potential tool that can

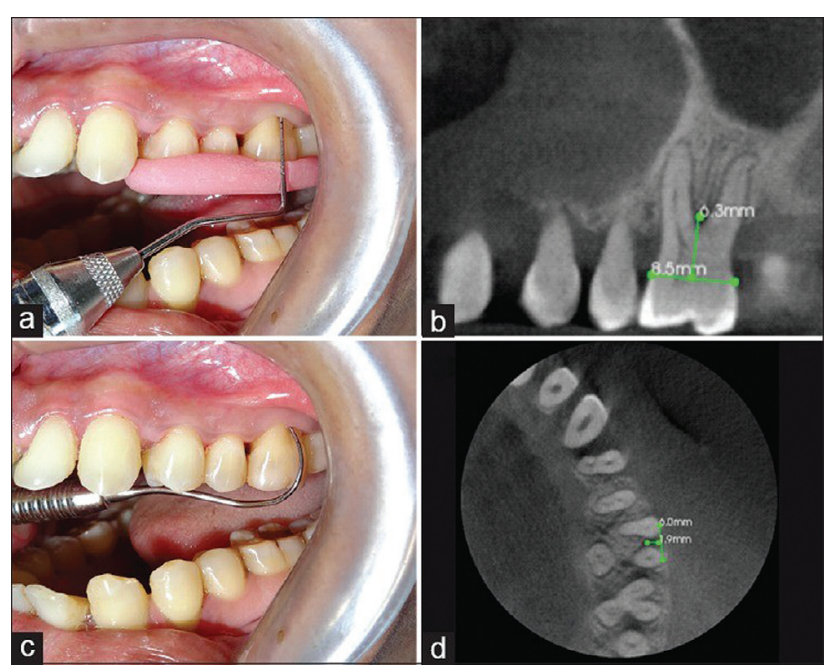

Fig. 3 Post-operative measurements of the same furcation defects. (a) Clinical measurement of the vertical component. (b) CBCT measurement of the vertical component. (c) Clinical measurement of horizontal component. (d) CBCT measurement of horizontal component. prevent surgical re-entry as a technique for assessing regenerative periodontal therapy outcomes. ${ }^{40}$

In 2010, Ito et al investigated the role of CBCT for the ideal placement of GTR membrane in inter-proximal defects. It allowed for detailed visualization of the characteristics of alveolar defects in all three dimensions. Using a template in axial dimension for the membrane made clinicians easier to arrive at a definitive conclusion. The membrane was easily adaptable over to the root surface on both the arches by using a template. The dimensions of the membrane were altered when viewed without СBCT. It also presented a shorter membrane trimming time and better accurate measurement in the volume assessment of bony defects and bone graft used in cleft surgeries. ${ }^{41}$

\section{CBCT in Implant Dentistry}

Radiographs play a crucial role in implant dentistry in assessing the bone levels and determining the prognosis of treatment outcomes.

Hu et al, in their study, evaluated the reliability of two presurgical radiographic methods, i.e., panoramic radiography and $\mathrm{CBCT}$, in implant planning concerning specific regions (maxilla and mandible). The results suggested that in mandible, digital panoramic radiography was safer to perform, while in maxilla, CBCT was better recommended. ${ }^{42}$

A study by Ekrish et al attempted to investigate the effect of exposure time on the accuracy of $\mathrm{CBCT}$ in implant sites on a dry skull. He found that reduced dose exposure time has no significant impact on the accuracy of the site measurements. ${ }^{43}$

Various other articles also suggest its ability to limit the rate of implant failures to a certain extent by providing the necessary information regarding the density, shape, height, and width of the alveolus at the implant site. ${ }^{44}$ 
Table 2 Summary

\begin{tabular}{|l|l|}
\hline Applications & Prognosis \\
\hline $\begin{array}{l}\text { Soft tissue } \\
\text { assessment }\end{array}$ & $\begin{array}{l}\text { Significant in determining } \\
\text { dimensions of periodontal soft and } \\
\text { hard tissues. }\end{array}$ \\
\hline Alveolar defects & $\begin{array}{l}\text { Potential for estimating intrabony } \\
\text { defects in three planes. }\end{array}$ \\
\hline $\begin{array}{l}\text { Furcation } \\
\text { involvement }\end{array}$ & $\begin{array}{l}\text { Adequate visualization of furcation } \\
\text { defects. }\end{array}$ \\
\hline $\begin{array}{l}\text { Regenerative } \\
\text { periodontal }\end{array}$ & $\begin{array}{l}\text { Presents shorter membrane } \\
\text { trimming time and accuracy in the } \\
\text { volume assessment of osseous } \\
\text { defects and bone grafts. }\end{array}$ \\
\hline Implant dentistry & $\begin{array}{l}\text { Limit the failures by providing } \\
\text { information on density, shape, } \\
\text { width, and height of alveolus. }\end{array}$ \\
\hline
\end{tabular}

\section{Conclusion}

CBCT can have an accurate and precise diagnostic value and deliver quantitative information on all the prevailing periodontal bone aspects. It is seen as a beneficial tool in visualizing craters, furcation defects, and bone defects.

However, CBCT is still not an efficient method for assessing bone quality and periodontal bone levels, while, on the contrary, conventional radiography is more precise. Also, the increased radiation emission for CBCT is still a limitation of the technique.

Therefore, the exact decision of whether to use CBCT in various applications in periodontology should be taken after careful consideration of its advantages, limitations, and risks (-Table 2).

\section{Conflict of Interest}

None declared.

\section{References}

1 Pihlstrom BL, Michalowicz BS, Johnson NW. Periodontal diseases. Lancet 2005;366(9499):1809-1820

2 Tugnait A, Clerehugh V, Hirschmann PN. The usefulness of radiographs in diagnosis and management of periodontal diseases: a review. J Dent 2000;28(04):219-226

3 Armitage GC. The complete periodontal examination. Periodontol 2000 2004;34(01):22-33

4 Benn DK. A review of the reliability of radiographic measurements in estimating alveolar bone changes. J Clin Periodontol 1990;17(01):14-21

5 Eickholz P, Hausmann E. Accuracy of radiographic assessment of interproximal bone loss in intrabony defects using linear measurements. Eur J Oral Sci 2000;108(01):70-73

6 Jeffcoat MK, Wang IC, Reddy MS. Radiographic diagnosis in periodontics. Periodontol 2000 1995;7(01):54-68

7 Arai Y, Tammisalo E, Iwai K, Hashimoto K, Shinoda K. Development of a compact computed tomographic apparatus for dental use. Dentomaxillofac Radiol 1999;28(04):245-248

8 Mozzo P, Procacci C, Tacconi A, Martini PT, Andreis IA. A new volumetric CT machine for dental imaging based on the cone- beam technique: preliminary results. Eur Radiol 1998;8(09): 1558-1564

9 Tsiklakis K, Donta C, Gavala S, Karayianni K, Kamenopoulou V, Hourdakis CJ. Dose reduction in maxillofacial imaging using low dose cone beam CT. Eur J Radiol 2005;56(03):413-417

10 Khadivi KO. Computed tomography: fundamentals, system technology, image quality, applications. 2nd ed. Med Phys 2006;33 (08):3076

11 Danforth RA, Dus I, Mah J. 3-D volume imaging for dentistry: a new dimension. J Calif Dent Assoc 2003;31(11):817-823

12 Ludlow JB, Davies-Ludlow LE, Brooks SL. Dosimetry of two extraoral direct digital imaging devices: NewTom cone beam CT and Orthophos Plus DS panoramic unit. Dentomaxillofac Radiol 2003;32(04):229-234

13 Danforth RA, Clark DE. Effective dose from radiation absorbed during a panoramic examination with a new generation machine. Oral Surg Oral Med Oral Pathol Oral Radiol Endod 2000;89(02): 236-243

14 Fleiner J, Hannig C, Schulze D, Stricker A, Jacobs R. Digital method for quantification of circumferential periodontal bone level using cone beam CT. Clin Oral Investig 2013;17(02):389-396

15 de Faria Vasconcelos K, Evangelista KM, Rodrigues CD, Estrela C, de Sousa TO, Silva MA. Detection of periodontal bone loss using cone beam CT and intraoral radiography. Dentomaxillofac Radiol 2012; 41(01):64-69

16 Nakajima K, Yamaguchi T, Maki K. Surgical orthodontic treatment for a patient with advanced periodontal disease: evaluation with electromyography and 3-dimensional cone-beam computed tomography. Am J Orthod Dentofacial Orthop 2009;136(03): 450-459

17 Dutta A, Smith-Jack F, Saunders WP. Prevalence of periradicular periodontitis in a Scottish subpopulation found on CBCT images. Int Endod J 2014;47(09):854-863

18 Dr Ashwini S, Dr Swatika K. Soft tissue thickness determination using CBCT in periodontics: a review. Int J Appl Dent Sci. 2017;3 (03):05-07

19 Januário AL, Barriviera M, Duarte WR. Soft tissue cone-beam computed tomography: a novel method for the measurement of gingival tissue and the dimensions of the dentogingival unit. J Esthet Restor Dent 2008;20(06):366-373, discussion 374

20 Gupta P, Jan SM, Behal R, Mir RA, Shafi M. Accuracy of cone-beam computerized tomography in determining the thickness of palatal masticatory mucosa. J Indian Soc Periodontol 2015;19(04): 396-400

21 Aljehani YA. Diagnostic applications of cone-beam CT for periodontal diseases. Int J Dent 2014;2014:865079

22 Özmeric N, Kostioutchenko I, Hägler G, Frentzen M, Jervøe-Storm PM. Cone-beam computed tomography in assessment of periodontal ligament space: in vitro study on artificial tooth model. Clin Oral Investig 2008;12(03):233-239

23 Jervøe-Storm PM, Hagner M, Neugebauer J, et al. Comparison of cone-beam computerized tomography and intraoral radiographs for determination of the periodontal ligament in a variable phantom. Oral Surg Oral Med Oral Pathol Oral Radiol Endod 2010;109(02):e95-e101

24 Braun X, Ritter L, Jervøe-Storm PM, Frentzen M. Diagnostic accuracy of CBCT for periodontal lesions. Clin Oral Investig 2014;18(04):1229-1236

25 Mol A, Balasundaram A. In vitro cone beam computed tomography imaging of periodontal bone. Dentomaxillofac Radiol 2008; 37(06):319-324

26 Vandenberghe B, Jacobs R, Yang J. Diagnostic validity (or acuity) of 2D CCD versus 3D CBCT-images for assessing periodontal breakdown. Oral Surg Oral Med Oral Pathol Oral Radiol Endod 2007;104 (03):395-401

27 Vandenberghe B, Jacobs R, Yang J. Detection of periodontal bone loss using digital intraoral and cone beam computed tomography 
images: an in vitro assessment of bony and/or infrabony defects. Dentomaxillofac Radiol 2008;37(05):252-260

28 Misch KA, Yi ES, Sarment DP. Accuracy of cone beam computed tomography for periodontal defect measurements. J Periodontol 2006;77(07):1261-1266

29 Mohan R, Mark R, Sing I, Jain A. Diagnostic accuracy of CBCT for aggressive periodontitis. J Clin Imaging Sci 2014;4(Suppl 2):2

30 Mengel R, Candir M, Shiratori K, Flores-de-Jacoby L. Digital volume tomography in the diagnosis of periodontal defects: an in vitro study on native pig and human mandibles. J Periodontol 2005;76(05):665-673

31 Noujeim M, Prihoda T, Langlais R, Nummikoski P. Evaluation of high-resolution cone beam computed tomography in the detection of simulated interradicular bone lesions. Dentomaxillofac Radiol 2009;38(03):156-162

32 Haas LF, Zimmermann GS, De Luca Canto G, Flores-Mir C, Corrêa M. Precision of cone beam CT to assess periodontal bone defects: a systematic review and meta-analysis. Dentomaxillofac Radiol 2018;47(02):20170084

33 Li F, Jia PY, Ouyang XY. Comparison of measurements on cone beam computed tomography for periodontal intrabony defect with intrasurgical measurements. Chin J Dent Res 2015;18(03):171-176

34 Leung CC, Palomo L, Griffith R, Hans MG. Accuracy and reliability of cone-beam computed tomography for measuring alveolar bone height and detecting bony dehiscences and fenestrations. Am J Orthod Dentofacial Orthop 2010;137(4, Suppl)S109-S119

35 Qiao J, Wang S, Duan J, et al. The accuracy of cone-beam computed tomography in assessing maxillary molar furcation involvement. J Clin Periodontol 2014;41(03):269-274

36 Walter C, Kaner D, Berndt DC, Weiger R, Zitzmann NU. Threedimensional imaging as a pre-operative tool in decision making for furcation surgery. J Clin Periodontol 2009;36(03):250-257
37 Umetsubo OS, Gaia BF, Costa FF, Cavalcanti MGP. Detection of simulated incipient furcation involvement by CBCT: an in vitro study using pig mandibles. Braz Oral Res 2012;26(04):341-347

38 Cimbaljevic MM, Spin-Neto RR, Miletic VJ, Jankovic SM, Aleksic ZM, Nikolic-Jakoba NS. Clinical and CBCT-based diagnosis of furcation involvement in patients with severe periodontitis. Quintessence Int 2015;46(10):863-870

39 Pajnigara N, Kolte A, Kolte R, Pajnigara N, Lathiya V. Diagnostic accuracy of cone beam computed tomography in identification and postoperative evaluation of furcation defects. J Indian Soc Periodontol 2016;20(04):386-390. Doi: 10.4103/0972-124X.192307

40 Grimard BA, Hoidal MJ, Mills MP, Mellonig JT, Nummikoski PV, Mealey BL. Comparison of clinical, periapical radiograph, and cone-beam volume tomography measurement techniques for assessing bone level changes following regenerative periodontal therapy. J Periodontol 2009;80(01):48-55

41 Takane M, Sato S, Suzuki K, et al. Clinical application of cone beam computed tomography for ideal absorbable membrane placement in interproximal bone defects. J Oral Sci 2010;52(01): 63-69

42 Hu KS, Choi DY, Lee WJ, Kim HJ, Jung UW, Kim S. Reliability of two different presurgical preparation methods for implant dentistry based on panoramic radiography and cone-beam computed tomography in cadavers. J Periodontal Implant Sci 2012;42(02):39-44

43 Al-Ekrish AA. Effect of exposure time on the accuracy and reliability of cone beam computed tomography in the assessment of dental implant site dimensions in dry skulls. Saudi Dent J 2012; 24(3-4):127-134

44 Hua Y, Nackaerts O, Duyck J, Maes F, Jacobs R. Bone quality assessment based on cone beam computed tomography imaging. Clin Oral Implants Res 2009;20(08):767-771 